\title{
How to Track Adaptation to Climate Change: A Typology of Approaches for National-Level Application
}

\author{
James D. Ford ${ }^{1}$, Lea Berrang-Ford ${ }^{1}$, Alex Lesnikowski ${ }^{1}$, Magda Barrera $^{1}$ and S. Jody Heymann ${ }^{2}$
}

\begin{abstract}
The need to track climate change adaptation progress is being increasingly recognized but our ability to do the tracking is constrained by the complex nature of adaptation and the absence of measurable outcomes or indicators by which to judge if and how adaptation is occurring. We developed a typology of approaches by which climate change adaptation can be tracked globally at a national level. On the one hand, outcome-based approaches directly measure adaptation progress and effectiveness with reference to avoided climate change impacts. However, given that full exposure to climate change impacts will not happen for decades, alternative approaches focus on developing indicators or proxies by which adaptation can be monitored. These include systematic measures of adaptation readiness, processes undertaken to advance adaptation, policies and programs implemented to adapt, and measures of the impacts of these policies and programs on changing vulnerability. While these approaches employ various methods and data sources, and identify different components of adaptation progress to track at the national level, they all seek to characterize the current status of adaptation by which progress over time can be monitored. However, there are significant challenges to operationalizing these approaches, including an absence of systematically collected data on adaptation actions and outcomes, underlying difficulties of defining what constitutes "adaptation", and a disconnect between the timescale over which adaptation plays out and the practical need for evaluation to inform policy. Given the development of new adaptation funding streams, it is imperative that tools for monitoring progress are developed and validated for identifying trends and gaps in adaptation response.
\end{abstract}

Key Words: adaptation response; adaptation tracking; climate change adaptation; evaluation; indicators; methodology; monitoring; outcome-based tracking, process-based tracking

\section{INTRODUCTION}

Steps to reduce further climate change are essential. Still, even if significant actions are taken, it is clear that adaptation to the existing level of climate change is critical. As recognition of the risks posed grows, adaptation has become a core element of climate policy and research (Pielke et al. 2007, Moser and Ekstrom 2010, Berrang-Ford et al. 2011, Smith et al. 2011). Recent years have witnessed the commitment of unprecedented levels of adaptation finance through the Green Climate Fund and by multi/bilateral donors (Liverman and Billett 2010, Donner et al. 2011, Fankhauser and Burton 2011, Klein and Moehner 2011, Jones et al. 2012), and national governments have to varying degrees recognized the need for adaptation (Biesbroek et al. 2010, Tompkins et al. 2010a, Ford and Berrang-Ford 2011, Ford et al. 2011, Lesnikowski et al. 2011, Preston et al. 2011). As adaptation financing increases and initiatives are developed, the need to monitor and evaluate progress on climate change adaptation is being increasingly recognized, as a means of evaluating the effectiveness of adaptation support, informing governance at various levels on adaptation needs, justifying funding allocation, and communicating to the public on adaptation.

Adaptation tracking is a component of intervention monitoring and evaluation that captures the extent to which adaptation is taking place as well as the success or effectiveness of adaptations in reducing vulnerability, from which a baseline of current action can be created and from which progress can be evaluated over time. Despite the importance of such activities, very little scholarship has focused on how to track adaptation and this is reflected in our limited and fragmented understanding of the state of adaptation, particularly at a global level (Gagnon-Lebrun and Agrawala 2007, Preston et al. 2009, Berrang-Ford et al. 2011, Ford et al. 2011). This partly reflects an absence of measurable outcomes or indicators from which to judge if and how adaptation is occurring, and a difficulty in defining what adaptation actually looks like in practice (Berrang-Ford et al. 2011, Ford et al. 2011, Gagnon-Lebrun and Agrawala 2007, Preston et al. 2009). In contrast to mitigation where progress can be tracked with reference to global concentrations of greenhouse gases, there is no easily definable adaptation metric. Neglect also reflects the "messiness" of adaptation, which is concerned with adjustments in human systems at different scales and by different actors, and which may be only partially developed in response to climatic stimuli. Moreover, the effectiveness of adaptation may not be evident for many decades, and is dependent on uncertain and unknown future climatic and socioeconomic conditions, while "successful" adaptation would likely be perceived differently by and among scholars, policy makers, and communities (Adger et al. 2005, Brooks et al. 2011, Villaneuva 2011, Lamhauge et al. 2012, Ford and King 2013). 
Reflecting these challenges, adaptation progress has rarely been measured. Yet if we are to document if adaptation is taking place, evaluate whether adaptation support is translating into actions, facilitate comparison of adaptations across regions and sectors, ensure resources are being invested in areas with the greatest need, and inform governance systems on the current status and gaps in adaptation action (see Themes 4 and 5 in this special edition), then systematic approaches and tools for tracking adaptation are needed (Berrang-Ford et al. 2011, Lesnikowski et al. 2011, Paterson et al. 2012, Poutiainen et al. 2013). We drew upon research on monitoring and evaluation in the general scholarship, and on emerging research in a climate change context, to develop a typology of approaches that offer promise for tracking adaptation globally at the national level. We took a national focus in our analysis, reflecting the need to develop comparative systematic approaches to provide a framework (complimentary to mitigation) with which to evaluate progress on adaptation. Many adaptation measures are best taken at the national level for reasons of both accountability and effectiveness, with national governments being a central pivot for adaptation planning, determining policy priorities, and distributing resources and support (Lesnikowski et al. 2011, Hanger et al. 2013). The need to evaluate national-level adaptations is already implicitly recognized by national reporting to the United Nations Framework Convention on Climate Change (UNFCCC), but is not systematized to the degree that metrics are readily accessible. Contributing to a nascent yet critically needed literature on challenges and methods for adaptation monitoring and evaluation, our work is an important first step for future work to expand, refine, and validate adaptation tracking approaches and tools, and it contributes to a number of themes in this special edition.

\section{TRACKING ADAPTATION: THE NEED AND CHALLENGES}

Among the research and policy community there is substantial and growing interest in adaptation tracking (Gagnon-Lebrun and Agrawala 2007, Harley et al. 2008, UNFCCC 2010b, Brooks et al. 2011, Lesnikowski et al. 2011, Preston et al. 2011, Poutiainen et al. 2013). This reflects a number of factors, including the need to examine the effectiveness of adaptation support mechanisms in order to evaluate adaptation funding, identify future priorities, and ensure the effective allocation of scarce resources. As adaptation funds have begun to be disbursed through the UNFCCC, for example, Parties, NGOs, and United Nations bodies have expressed the need to examine the success of funds invested for accountability purposes and to ensure resources are being effectively utilized. The UNFCCC's Adaptation Committee, created through the Cancun Adaptation Framework, has been tasked with "[c] onsidering information communicated by Parties on their monitoring and review of adaptation actions, support provided and received, possible needs and gaps and other relevant information, including information communicated under the Convention, with a view to recommending what further action may be required, as appropriate" (UNFCCC 2010a). Similarly, some governments have begun to develop adaptation indicators to measure progress towards meeting the objectives of national adaptation strategies, review uptake of adaptation, and promote transparency in the effectiveness of adaptation initiatives. For example, the Adaptation SubCommittee in the U.K. has identified indicators for both impact and vulnerability outcomes and the uptake of adaptation action (Harley et al. 2008, Krebs et al. 2010, Harvey et al. 2011, Krebs et al. 2011). Likewise in Germany, an initial set of indicators for measuring progress towards meeting the objectives of the national adaptation strategy have been proposed (Schonthaler et al. 2010).

Reflecting this interest, there is a small but growing literature on monitoring and evaluation for climate change adaptation. This scholarship has theorized key characteristics that define successful or effective adaptation and has focused on specific adaptation interventions or programs, and has been primarily driven by the needs of development agencies and multi/ bilateral donors to measure the success of supported adaptation initiatives in low income nations (Adger et al. 2005, de Bruin et al. 2009, Preston et al. 2009, Biesbroek et al. 2010, Tompkins et al. 2010b, Brooks et al. 2011, Hambling et al. 2011, Preston et al. 2011, Villaneuva 2011, Lamhauge et al. 2012, Sovacool 2012, Sovacool et al. 2012, Hanger et al. 2013). As noted above, some governments have also begun to develop indicators for evaluating progress towards meeting the goals of adaptation strategies. Our work has made important contributions for adaptation evaluation, but global operationalization at a national level and for purposes of adaptation tracking are constrained by limited attention to developing tools by which adaptation can be systematically tracked over time and across regions, an absence of debate on metrics by which actions can be monitored, and limited standardization in approaches.

The inherent nature of adaptation complicates monitoring and evaluation efforts at a global level, and three main challenges present obstacles for developing approaches to track adaptation.

- There is a need to define what adaptation looks like in practice if we are to develop indicators and identify appropriate data sources for monitoring and evaluation. Here, the commonly used definition of adaptation as adjustments in human systems in response to actual or expected climatic stimuli or their effects, which moderate harm, offers little practical guidance for global tracking. Adaptations can take many forms, reflecting divergent conceptualizations of vulnerability driving action, the goals and functions of adaptation in different contexts, and a myriad of sectors and scales at which adaptation 
takes place (see Themes 1 and 3 in this special edition). While some adaptations may be developed specifically to cope with climate change and be framed as such (e.g., hard infrastructural responses), adaptations often involve policy, legal, administrative, institutional, and financial responses to reduce sensitivity and increase adaptive capacity/resilience. These may be only partially developed in response to climatic stimuli, may not be framed as climate adaptations, may be mainstreamed into existing policies, and may not have clear outcomes by which their effectiveness or success in reducing vulnerability can be assessed.

- Characteristics of success need to be identified to capture the effectiveness of adaptations in reducing vulnerability. While some adaptations may have direct and measureable outcomes, in many instances impacts on vulnerability are not directly visible and/or will be evident only over many decades, with different interpretations on what characterizes "success" (see Themes 1, 3, and 5 in this special edition). Disentangling the role played by adaptation is further complicated by the fact that baseline climatic and socioeconomic conditions that determine adaptation effectiveness also change, potentially rendering interventions ineffective. Moreover, adaptation strategies that are successful in the short term may be maladaptive in the long term, exacerbating vulnerability due to altered behavior (e.g., morale hazard), changed patterns of development, displacement of risks to other groups, and creation of path dependency, and in light of challenges of maintaining interventions (e.g., upkeep of hazard protection measures) (Barnett and O'Neill 2010, Fazey et al. 2011). Some policy evaluation scholarship focuses on process characteristics of policy development and implementation instead of on the evaluation of effectiveness, but debate on these components in an adaptation context remains in its infancy.

- Appropriate data sources need to be identified to facilitate the development and tracking of indicators. For the purposes of evaluating progress on adaptation globally, data sources need to: (i) provide information on adaptation for a large number of countries to facilitate national-level comparative analysis, (ii) be systematically collected and follow standardized guidelines so comparison reflects real trends in adaptation as opposed to nature of data collection, (iii) provide sufficient detail for adaptations to be characterized, and (iv) be consistent in reporting over time and be collected at regular intervals. As noted above, few existing data sources meet these requirements, and there has been little work examining how current data sources could be used to systematically track adaptation.
Research on general policy evaluation and emerging scholarship in the climate change field can provide a foundation for conceptualizing and developing new frameworks for adaptation tracking at the national level. In the following sections we propose a typology of approaches that provide potential starting points for development of a global adaptation tracking framework (Table 1). While we acknowledge that these approaches intersect, each has its distinct attributes and the typology can help us begin to discuss and evaluate the different ways by which adaptation can be tracked.

In developing the typology, our intention is not to rank or identify which approach is "best" but rather outline how and where different approaches can be used and for what purposes. The selection of approach will ultimately reflect the needs of users and goals of adaptation tracking. National governments, for example, can be spurred to action by seeing how their progress compares to that of other nations. Both global intergovernmental organizations and civil society can use comparative quantitative measures as a source of accountability and to identify and prioritize broad-level intervention needs (e.g., to inform adaptation funding decisions). In these instances, the ability of an approach to systematically track adaptation across regions and sectors drawing upon standardized data (i.e., generality) is likely to be highly valued. In other situations, the ability of an approach to provide quantifiable estimates of avoided negative impacts due to adaptation (i.e., additionality) may be a priority (e.g., for adaptation funding through the UNFCCC). Detailed qualitative measures can also be used to provide information to policy makers and to those providing technical expertise to them on options that can be pursued. Here, the ability of an approach to provide comparative insights with other regions, and also capture the processes through which adaptations were developed for purposes of evaluating long-term effectiveness are important.

\section{OUTCOME EVALUATION APPROACHES: STRENGTHS AND LIMITATIONS FOR MONITORING ADAPTATION}

Outcome evaluation approaches measure adaptation progress and effectiveness in relation to avoided climate change impacts (i.e., the ultimate goal of adaptation). While often treated as a gold standard in the general monitoring and evaluation literature, they have not been widely used in an adaptation context, reflecting the difficulty of attributing reduced impact specifically to adaptation, where success may not be apparent for decades and where impacts averted in the future are tricky to estimate. This temporal disconnectproactive intervention to avert future theorized but unmeasured impacts-differentiates adaptation tracking efforts from standard approaches to outcome evaluation. Nevertheless, outcome approaches are commonly used in the general policy evaluation literature and for issues of 
Table 1. Typology of approaches for adaptation tracking

\begin{tabular}{|c|c|c|c|c|c|}
\hline & Tracking approaches & Characteristics & Data sources & Strengths & Limitations \\
\hline Outcome-based & $\begin{array}{l}\text { Outcome evaluation: } \\
\text { reduced negative } \\
\text { climate change } \\
\text { impacts }\end{array}$ & $\begin{array}{l}\text { - Track climate-related } \\
\text { losses, mortality, and } \\
\text { morbidity, over time and in } \\
\text { relation to adaptation } \\
\text { - Examine impacts of } \\
\text { climatic hazard event before } \\
\text { and after adaptation }\end{array}$ & $\begin{array}{l}\text { - Natural hazard loss } \\
\text { databases (e.g., } \\
\text { emergency events } \\
\text { database) }\end{array}$ & $\begin{array}{l}\text { - Quantification of } \\
\text { adaptation progress and } \\
\text { effectiveness } \\
\text { - Metrics can be } \\
\text { monitored over time } \\
\text { - Availability of } \\
\text { standardized global } \\
\text { datasets of hazards } \\
\text { losses and mortality } \\
\text { across regions } \\
\text { - Legitimacy within } \\
\text { policy evaluation } \\
\text { community }\end{array}$ & $\begin{array}{l}\text { - Applicable only where } \\
\text { outcomes are directly } \\
\text { observable } \\
\text { - Difficulty of inferring } \\
\text { causality between } \\
\text { outcome and adaptation } \\
\text { - Potential for } \\
\text { maladaptation not } \\
\text { captured } \\
\text { - Limited applicability to } \\
\text { "soft" and mainstreamed } \\
\text { adaptations } \\
\text { - Does not measure } \\
\text { outcomes from adapting } \\
\text { to wider (nonevent- } \\
\text { oriented) climate change }\end{array}$ \\
\hline $\begin{array}{l}\text { Preparedness- , } \\
\text { process- ,and } \\
\text { policy-based }\end{array}$ & $\begin{array}{l}\text { Process-based } \\
\text { approaches: process } \\
\text { through which } \\
\text { adaptations are } \\
\text { developed and } \\
\text { implemented in } \\
\text { pursuance of a } \\
\text { desired outcome or } \\
\text { objective }\end{array}$ & $\begin{array}{l}\text {-With regard to adaptation, } \\
\text { evidence of: political } \\
\text { leadership; institutional } \\
\text { organization; stakeholder } \\
\text { involvement; climate change } \\
\text { information; appropriate use } \\
\text { of decision-making } \\
\text { techniques; and } \\
\text { consideration of barriers to } \\
\text { adaptation, funding, } \\
\text { technology development, and } \\
\text { adaptation research }\end{array}$ & $\begin{array}{l}\text { - Speeches at } \\
\text { Conference of the } \\
\text { Parties meetings } \\
\text { - Attendance at } \\
\text { Conference of the } \\
\text { Parties meetings } \\
\text { - Leadership identified } \\
\text { in UNFCCC National } \\
\text { Communications or } \\
\text { National Adaptation } \\
\text { Programmes of Action } \\
\text { - UNFCCCC National } \\
\text { Communications } \\
\text { - National assessments } \\
\text { - National Adaptation } \\
\text { Programmes of Action } \\
\text { - Adaptation inventories }\end{array}$ & $\begin{array}{l}\text { - Not dependent on } \\
\text { outcomes being visible } \\
\text { - Capture the key } \\
\text { processes that are } \\
\text { believed to underpin } \\
\text { effective and successful } \\
\text { adaptation }\end{array}$ & $\begin{array}{l}\text { - Limited systematically } \\
\text { collected data on process } \\
\text { of adaptation } \\
\text { development and } \\
\text { implementation } \\
\text { - Limited transferability } \\
\text { across nations } \\
\text { - Time intensive } \\
\text { - Unproven link to } \\
\text { adaptation success }\end{array}$ \\
\hline
\end{tabular}




\begin{tabular}{|c|c|c|c|c|}
\hline $\begin{array}{l}\text { Analyzing policies } \\
\text { and programmatic } \\
\text { approaches: } \\
\text { monitoring and } \\
\text { comparison of } \\
\text { reported } \\
\text { adaptation actions } \\
\text { and } \\
\text { their characteristics }\end{array}$ & $\begin{array}{l}\text { - Analysis of characteristics } \\
\text { of reported adaptations and } \\
\text { comparison across regions, } \\
\text { by vulnerability categories, } \\
\text { over time, and with respect } \\
\text { to adaptation "obligations" }\end{array}$ & $\begin{array}{l}\text { - UNFCCC National } \\
\text { Communications } \\
\text { - National Adaptation } \\
\text { Programmes of Action } \\
\text { - Adaptation inventories } \\
\text { - National adaptation } \\
\text { assessments }\end{array}$ & $\begin{array}{l}\text { - Not dependent on } \\
\text { outcomes being visible } \\
\text { - Systematic and } \\
\text { quantitative analysis of } \\
\text { progress } \\
\text { - Comparability across } \\
\text { nations } \\
\text { - Suited for global } \\
\text { application } \\
\text { - Amenable for rapid } \\
\text { assessment }\end{array}$ & $\begin{array}{l}\text { - Success not directly } \\
\text { measured } \\
\text { - Results subject to } \\
\text { reporting bias }\end{array}$ \\
\hline $\begin{array}{l}\text { Examining Measures } \\
\text { of changing } \\
\text { vulnerability: } \\
\text { measurement of } \\
\text { change in } \\
\text { vulnerability in } \\
\text { relation to adaptation }\end{array}$ & $\begin{array}{l}\text { - Monitor aggregate } \\
\text { vulnerability indices in } \\
\text { relation to adaptation actions } \\
\text { - Focus on specific indicators } \\
\text { which capture the generic } \\
\text { determinants of vulnerability } \\
\text { (e.g., access to education; } \\
\text { poverty; health; and } \\
\text { inequality) } \\
\text { - Examine specific } \\
\text { components of sensitivity } \\
\text { and adaptive capacity to } \\
\text { climate change impacts }\end{array}$ & $\begin{array}{l}\text { • Climate Change } \\
\text { Vulnerability Index } \\
\text { • Environmental } \\
\text { Sustainability Index } \\
\text { • Global Climate Risk } \\
\text { Index } \\
\text { • GAIN Index }\end{array}$ & $\begin{array}{l}\text { - Not dependent on } \\
\text { outcomes being visible } \\
\text { - Readily available } \\
\text { vulnerability indices } \\
\text { globally } \\
\text { - Amenable for rapid } \\
\text { assessment }\end{array}$ & $\begin{array}{l}\text { - Inability to capture } \\
\text { determinants of } \\
\text { vulnerability } \\
\text { - Fundamental } \\
\text { disagreement between } \\
\text { indices on magnitude of } \\
\text { vulnerability } \\
\text { - Challenge of linking } \\
\text { change in indices to } \\
\text { adaptation }\end{array}$ \\
\hline
\end{tabular}

comparable scope and complexity to adaptation. For instance, Kahn (2003) uses hazard-related mortality as an outcome indicator to judge progress in coping with disasters in the United States, hypothesizing that a reduction in deaths per disaster between 1970 and 2001 to be indicative of effective preparedness interventions. Similarly, McMichael et al. (2004) note the potential applicability of standard epidemiological techniques for estimating the avoided impact of climate-related disease burden attributable to public health interventions and by which adaptation success could be quantified and monitored.

Outcomes by which adaptation can be evaluated relate to the actual manifestation of system vulnerability or impact. Where relevant global data exist, these outcomes can be quantified, establishing a baseline from which progress can be tracked vis-à-vis adaptation actions over time. Adaptation examples of outcome indicators could include tracking climate-related disaster losses, mortality, and morbidity in response to documented national-level adaptations. Global datasets on relevant outcome indicators are widely available (e.g., the emergency events database), and combined with adaptation inventories could be used to identify cases where a change in outcome indicators coincides with adaptation actions. Though it will be difficult to infer causality-that a particular adaptation action(s) resulted in a particular adaptation outcome(s) — when applied systematically and regularly, such approaches offer opportunities to build evidence for adaptation impact, particularly when complimented by process-based evaluations (section 4). Comparison across nations with similar exposure to climatic risks and similar socioeconomic conditions but different adaptation and risk reduction profiles could also be used to further examine adaptation success.

Outcome approaches can also be opportunistically used to track specific adaptation actions, dependent on certain circumstances under which outcomes can be assessed empirically (Brooks et al. 2011). Examining the impacts of extreme events of a similar magnitude in terms of mortality, morbidity, and insured losses in a specific location or region before and after an adaptation intervention is one such approach, although the opportunistic nature limits the ability to conduct cross-country/sector comparisons and systematically track adaptation globally.

The strength of outcome approaches for adaptation tracking lies in their ability to systematically quantify adaptation progress and effectiveness, providing metrics that can be 
monitored over time, across regions, and for multiple vulnerabilities. They have a long history of use in the public health sphere where outcome data are readily available at a national level (e.g., mortality, morbidity, DALYs) and are often disaggregated by health outcome (e.g., malnutrition, disease prevalence, etc.), with interested users in a climate change context potentially including the World Health Organization (WHO), World Bank, and regional development banks. The focus on avoided impacts is also consistent with adaptation support mechanisms of the UNFCCC and by donors who typically require direct indicators of success, measurement of "additionality", and accountability on spending. Drawing upon established policy-evaluation techniques, outcome approaches also have legitimacy within wider policy circles and can be used to clarify if an intervention was a good investment (Glasgow et al. 1999, Campbell et al. 2000, Rubin et al. 2001). These are important considerations for adaptation, which has struggled to get political attention and allocation of scarce resources, with public sector decision making often driven by economic efficiency (Adger et al. 2005, Burton 2006, Ford and Berrang-Ford 2011, Pielke et al. 2007).

However, caution is needed when using outcome approaches, as they depend on avoided impacts being visible and measurable. Outcome approaches also imply that there is an existing record of impacts over time, with implications for our ability to proactively avert emerging impacts before they occur and, therefore, before they are measured. Attribution is particularly problematic at a national level, with outcomes through which adaptation success can be measured being influenced by many factors besides climate policy and not always being tangible (Glasgow et al. 1999, Campbell et al. 2000, Jakeman et al. 2006, Gagnon-Lebrun and Agrawala 2007). Adaptation measurement would benefit from the use of existing tools in multivariate modeling and mixed-methods approaches to explore and tease apart the extent to which adaptation interventions can be causally linked to defined outcomes. Such approaches require large systematic datasets and replication, however; while some such global data exist, they have not yet been developed or validated for adaptation tracking efforts.

Furthermore, as Adger et al. (2005) note, adaptation success/ effectiveness often depends on the sequence and interaction of adaptations over time and as the climate changes. An adaptation may therefore appear effective in the short term if it is deemed to reduce immediate risk, but in the long term may be maladaptive: for example, coastal protection measures may protect low-lying regions but increase vulnerability to high-magnitude storm surges by promoting development in high-risk locations (Kates et al. 1985, Kates et al. 2006). For this reason, outcome measures only fully capture short-term effectiveness. Similarly, an adaptation may reduce vulnerability in a specific location/for a specific group but displace impacts to other regions and groups, potentially increasing the overall vulnerability (Barnett and O'Neill 2010). More broadly, the policy evaluation scholarship has critiqued the pitfalls of overemphasis on specific outcomes, which prioritize measurable "hard" interventions with readily visible impact, downplaying "softer" adaptations which may be more likely to be effective in reducing vulnerability (Campbell et al. 2000, Laville 2000, Rychetnik et al. 2002, Adger et al. 2005, Preston et al. 2009, Sovacool 2011). Indeed, outcome-based approaches have limited applicability for tracking mainstreamed adaptations, where adaptation is integrated into ongoing policy initiatives and often focuses on enhancing adaptive capacity, and where there are no readily available metrics.

\section{SYSTEMATIC OPTIONS FOR TRACKING ADAPTATION}

While the nature of adaptation limits the applicability of outcome measures for monitoring and evaluation, a range of systematic measures are available to assess various stages of adaptation, from adaptation readiness to processes undertaken to advance adaptation, policies, and programs implemented to adapt, and measures of the impact of these policies and programs on changing vulnerability. Each is discussed in turn below and involves developing indicators or proxies of adaptation to monitor.

\section{Measures of adaptation readiness}

One approach for tracking adaptation involves evaluating the strength and existence of governance structures and processes that determine the presumed ability (i.e., readiness) of nations to build support for action and effectively develop, implement, and monitor adaptation interventions. Adaptation readiness evaluates the extent to which key governance factors assumed to be fundamental in determining if and how adaptation takes place are present. The extent to which a nation is ready to adapt can therefore be used as a proxy for tracking adaptation. It is noteworthy that adaptation readiness differs from adaptive capacity: the latter focuses on conditions determining the ability to adapt, while readiness examines what has been undertaken to lay the ground for adaptation to take place (Ford and Kint 2013).

Research on adaptation planning and intervention at multiple levels has identified key components of governance structures that are important for identifying effective policy strategies, removing or transcending barriers to adaptive action, and enhancing readiness to adapt (see Themes 3, 4, and 5 in this special edition) (Fussel and Klein 2006, Smit and Wandel 2006, Fussel 2007, Biermann et al. 2010, Biesbroek et al. 2010, Ford et al. 2010, Gupta et al. 2010, Moser and Ekstrom 2010, Berrang-Ford et al. 2011, Preston et al. 2011, Termeer et al. 2012). Smith et al. (2009) combined insights from this work 
in an architecture of adaptation, identifying nine components essential for adaptation implementation and which can be used to evaluate adaptation readiness:

- Political leadership from the chief executive stating the importance of adaptation is essential for overcoming the bureaucratic resistance that is common with regard to complex problems, like adaptation, that cut across jurisdictions and can inhibit the collaboration necessary for implementing policy.

- Institutional organization is important in constraining or enabling adaptation, with research indicating adaptation interventions and planning are effective where a single government agency takes coordinating lead for adaptation or an interagency group is created to oversee adaptation activities.

- Stakeholder involvement is needed to ensure adaptation policies are designed to meet the needs of those affected by climate change, promote stakeholder buy-in for adaptation, identify opportunities and constraints to adaptation which need to be addressed, and locate potential for mainstreaming.

- Climate change information is important for informing decision makers in assessing risks, examining costs of action and inaction, prioritizing needs, and building support for taking action.

- Appropriate use of decision-making techniques is necessary given the inherent uncertainties surrounding climate change and the "hidden hazards" nature of the problem which can cause policy makers to postpone and avoid action.

- Explicit consideration of barriers to adaptation is essential given the barriers to adaptation that are known to exist and are likely to constrain or be incompatible with adaptation policy.

- Funding for adaptation is needed as few adaptation policies can implemented solely with existing funding streams.

- Technology development and diffusion is important for expanding the range of adaptation possibilities by increasing opportunities and/or reducing costs. This in turn can help decision makers tackle difficult choices and address problems around competing values.

- Adaptation research is needed to understand what society needs to adapt to, identify options available to adapt, and understand how adaptation can be effectively promoted and implemented.

While this architecture was proposed by Smith et al. (2009) as a decision-support heuristic, it also provides a systematic means of identifying and evaluating the extent to which nations are ready for adaptation from which indicators can be developed to monitor progress over time. Each component in the architecture will play an important role in facilitating adaptation in specific contexts, and while not all components need to be present for effective adaptation, the presence of only a small subset is unlikely to provide a strong basis for action. An example of indicators and sources of information which may be used are provided in Table 2, with indicators combining binary variables (e.g., yes, no; present, absent), ordinal rankings (e.g., high, medium, low), and continuous measures (e.g., amount invested in adaptation research). Indicators can be combined to provide an overall readiness index that can be analyzed to characterize the extent to which nations are ready for adaptation, examine how readiness differs between nations and sectors, profile components of readiness that nations are most and least prepared for, identify key barriers, and track progress over time.

Adaptation readiness approaches complement other methodologies for adaptation tracking by capturing the extent to which governance structures and processes needed to facilitate effective implementation of adaptation are in place. They do not depend on outcomes being identified and reported on and the challenges herein. While it is important to note that readiness may not necessarily translate into effective adaptation, absence of key components is unlikely to provide a strong basis for action (Smith et al. 2009), and progress can therefore be used as a proxy of increasing likelihood of adaptation taking place. Nevertheless, to our knowledge adaptation readiness has not been empirically applied for adaptation monitoring and evaluation, and the concept has not received widespread attention in the scholarship. Notably, readiness indicators have not been validated; while expert knowledge, experience, and theory suggest these processes are important for adaptation readiness, we know little about whether and how such determinants actually drive adaptation action and success on the ground. Thus, the potential challenges of using diverse data sources to extract information on readiness remain unknown, and the ability to create systematic, rigorous indices are untested, emphasizing the importance of pilot application.

\section{Process-based approaches}

Process-based approaches focus on the process through which interventions are developed and implemented in pursuance of a desired outcome or objective. These have emerged in the general policy evaluation scholarship in response to concerns over the ability of outcome evaluation techniques to fully capture dimensions of success, and importance of capturing the process of learning and decision making not easily discernible in output indicators. In an adaptation context, interest in process approaches reflects the temporal disconnect between the timescale over which adaptation effectiveness is often manifest and the practical need to conduct evaluation. Theoretical work has identified general process characteristics 
Table 2. Potential indicators and sources of information for evaluating readiness for adaptation.

\begin{tabular}{lll}
\hline \hline Adaptation architecture & Indicator & Sources of information \\
\hline Political leadership & $\begin{array}{l}\text { Statements of importance and need for adaptation by } \\
\text { national leaders; inclusion of adaptation as a policy priority }\end{array}$ & $\begin{array}{l}\text { Speeches at Conference of the Parties meetings; attendance } \\
\text { at Conference of the Parties meetings; leadership identified } \\
\text { in UNFCCC National Communications or National }\end{array}$ \\
& & Adaptation Programmes of Action
\end{tabular}

Institutional organization

Stakeholder involvement

Climate change information

Appropriate use of decision making techniques

Consideration of adaptation barriers

Funding

Technology

Adaptation research
Lead department / agency identified OR interagency group established; presence of adaptation planning document
Lead organization specified for UNFCCC National Communications or National Adaptation Programmes of Action; adaptation planning documents

National assessments; stakeholders consultation noted in UNFCCC National Communications; NAPA assessments and policy consultation; co-authorship on publications

National climate change assessments produced; existence of NAPA; completion of UNFCCC National

Communications; nation-specific peer-reviewed literature

Use of decision-making tools (e.g., cost benefit analysis, matrices etc); use of climate change adaptation frameworks NAPA

Policy reviews to identify barriers

UNFCCC National Communications; national assessments; NAPA

UNFCCC National Communications; national assessments; climate change programs / policies / announcements; peerreviewed literature

UNFCCC National Communications; national assessments; peer-reviewed and gray lit; National Adaptation Programmes of Action

UNFCCC National Communications; national assessments; climate change programs / policies / announcements; peerreviewed literature by which adaptation success can be evaluated (see Themes 2 to 5 in this special edition). While developed and applied primarily at a project level and stopping short of identifying metrics by which adaptation can be tracked, our work provides a theoretical basis for the development of national-level process indicators that can be used globally.

Project-level assessments of adaptation typically compare the characteristics of adaptation development and implementation to theoretically derived components of adaptation success and best practice. This work involves detailed evaluation of specific interventions from start to finish, using evaluation criteria-including effectiveness, efficiency, equity, legitimacy, flexibility, acceptability, mainstreaming, and sustainability- to capture key dimensions of success, and using components of best practice in policy development-including level and nature of stakeholder engagement, and consideration of vulnerable groups (Yohe and Tol 2002, Adger et al. 2005, Lemos and Morehouse 2005, Fussel 2008, de Bruin et al. 2009, Preston et al. 2009, Smith et al. 2009, Ford et al. 2010, Moser and Ekstrom 2010, Brooks et al. 2011, Dilling and Lemos 2011, Ford and Berrang-Ford 2011, Preston et al. 2011). While particularly useful for examining projects and establishing a baseline of adaptation in specific places, applicability at a global scale is challenged by data and time requirements. It is possible, however, that general indicators capturing key process components could be developed to characterize the 
current status of adaptations globally from which future progress could be tracked. For example, national adaptation plans often contain considerable information on the process of adaptation development (e.g., Preston et al. 2011). Nevertheless, global application remains complicated by the challenge of obtaining systematic descriptions of the adaptation process across nations. Data sources-including adaptation inventories, UNFCCC National Communications, and IPCC reports, for instance-often provide limited comparable information from which to systematically evaluate the process through which adaptations are developed and implemented, while there are too few detailed nationallevel adaptation case studies (e.g., Tompkins et al. 2010a) to provide a comprehensive and representative characterization of adaptation globally.

\section{Analyzing policies and programmatic approaches}

Given the time lag between adaptation actions and likely measurable outcomes, an important complement to outcome measures is monitoring policies and programs. While this presents significant challenges, including defining appropriate dimensions on which to compare policies across countries and finding globally comparative data sources, they have been used to compare and monitor policy responses across all United Nations countries to issues such as improving labor conditions, addressing poverty, and children's needs (Earle et al. 2011, Heymann et al. 2011, Schliwen et al. 2011, Heymann and McNeill 2013). In addition to monitoring policy development, these approaches have allowed examination of the extent to which countries comply with international agreements, whether they have a positive impact on population health and well-being (Heymann et al. 2011), and whether they are affordable (Earle et al. 2011). Others have also used policy tracking to monitor progress towards explicit globally defined goals. For example, Countdown to 2015 uses countrylevel data to track progress on interventions necessary to fulfill goals to improve maternal and child health and mortality under the Millennium Development Goals. Using a number of demographic, equity, health, and care indicators, Countdown to 2015 compiles longitudinal data that demonstrates progress toward meeting Millennium Development Goals four and five, identifies gaps in knowledge and action, and suggests strategies for addressing these gaps (Requejo et al. 2012).

Informed by this scholarship, such techniques can be adapted to systematically identify and characterize how actual adaptations are occurring at the national level. Here, a baseline of current action can be established with reference to the extent of adaptations taking place, while adequacy can be examined via the nature of adaptations reported and compared to adaptation commitments and needs identified (types of action, scale, vulnerabilities responded to, stakeholder involvement, etc.). Variations of this approach have been employed in the adaptation scholarship. Gagnon-Lebrun and Agrawala (2007) for example, examine attention paid to adaptation in the $2^{\text {nd }}$ and $3^{\text {rd }}$ National Communications of Annex-1 nations to the UNFCCC through content analysis, using this to examine the state of adaptation in developed nations. Poutiainen et al. (2013) use web-content of civil society organizations to document adaptation taking place in this sector to reduce climate-related health vulnerabilities in Canada. Berrang-Ford et al. (2011) and Ford et al. (2011) use reporting on adaptation actions in the peer-reviewed literature to create a baseline understanding of how adaptation is taking place, while Lesnikowski et al. (2011) use the $5^{\text {th }}$ National Communications of Annex I nations to identify and characterize discrete adaptation actions reported on in a health context (Lesnikowski et al. in press- $a$, Lesnikowski et al. in press-b).

This work uses adaptation reporting as a proxy for adaptation actions, coding individual actions according to the stimulus motivating the response, who or what adapts, adaptation activities and outcomes, level of action, and constraints to and facilitators of adaptation, from which descriptive and inferential statistics can be used to monitor, evaluate, and compare trends. Lesnikowski et al. (2011), for instance, compare groupings of high, medium, and low adaptors, and evaluate success according to the extent to which health adaptations were informed by impacts and vulnerability assessments, breadth of risks addressed, consideration of vulnerable groups, integration of evaluation mechanisms into adaptations, stage of intervention (recognition, groundwork, action), and extent to which climate change concerns are integrated into interventions. Using the same dataset, Lesnikowski et al. (in review) calculate two indices to capture the range of types of action being taken within each Annex I country (Adaptation Response Score), and the range of health vulnerabilities being addressed at the groundwork and adaptation levels (Health Areas Score), providing metrics by which adaptation progress could be tracked over time.

A key strength of focusing on reported adaptation actions is the ability to systematically and quantitatively characterize the current state of adaptation at a national level using existing sources of information. This approach is particularly suited for monitoring progress over time, making comparative analysis between and across regions and sectors, and for identifying general trends and patterns. Using self-reported data, the national communications also allow for further inferences about policy priorities at a national level. While research has primarily used reporting to the UNFCCC and peer-reviewed scholarship to document adaptations, additional data sources could include databases of NGOs, aid agencies, national governments, and international bodies. At the same time, caution is required when interpreting the results of action-based studies. Many adaptations are undocumented, success is not directly measured, and results are subject to reporting bias. The detail provided in reports such as the National Communications can also vary significantly, 
reflecting capacity challenges and reporting as much as actual experience with adaptation. For this reason, such approaches are best suited for identifying general trends as opposed to country specific characteristics, and need to be interpreted as proxies of adaptation, a snapshot of what is going on. As such they hold particular promise for global adaptation tracking, with users potentially including United Nations bodies (for example, UNEP, UNDP, UNFCCC) and other global organizations (for example, World Bank) with an interest in examining the state of adaptation across nations and identifying leaders and laggards alongside nations interested in comparing their adaptation profiles to other countries and seeking best-practice examples.

\section{Examining measures of changing vulnerability}

While outcome approaches focus on the direct manifestations of reduced risk following adaptation, indirect or proxy measures of vulnerability reduction can also be used to infer successful adaptation. Since the 1990s a number of projects have created indices of vulnerability, focusing predominantly on the national to global scale (O'Brien et al. 2004, Brooks et al. 2005, Eriksen and Kelly 2007, Klein 2009). While typically used to locate "hot spots" of climate risk, predict future vulnerabilities, and inform adaptation planning, they can also provide a baseline characterization of vulnerability from which adaptation success can be evaluated and monitored. At a very broad level, this could involve: monitoring aggregate vulnerability indices at a national level in relation to adaptation actions; focusing on specific indicators which capture the generic determinants of vulnerability, including access to education, poverty, health, and inequality; or, examining specific components of sensitivity and adaptive capacity to climate change impacts such as identifying regional shifts in land use in high-risk locations (Brooks et al. 2005, Brooks et al. 2011). There have been numerous critiques however, concerning the extent to which vulnerability indices are able capture the dynamic processes shaping vulnerability, with scholars pointing to the wide diversity in national vulnerability rankings produced by different index methods, and arguing that results are largely methodologically driven (Eriksen and Kelly 2007, Barnett et al. 2008, Fussel 2009, Klein 2009, Hinkel 2011), while there has been minimal validation of whether the included variables are necessary precursors to adaptation. Moreover, many indices represent general socioeconomic development trends, where disentangling the role played by adaptation is problematic.

\section{CONCLUSION}

The funding of adaptation activities is now a major theme of international climate negotiations and domestic climate policy, and there is increasing evidence that governments, industry, and NGOs are investing in adaptation. We can expect this to increase as the risks of not adapting become evident, climate change impacts become visible, and the Green Climate Fund begins to mobilize resources for adaptation in the global south. With this increasing emphasis comes the necessity of monitoring and evaluating adaptation progress globally at the national level for purposes of accountability, and to justify continued support, ensure efficiency in the allocation of scarce resources, identify gaps in intervention, inform governance systems on adaptation progress, and spur governments on the need to adapt. However, our ability to track adaptation, is constrained by the challenge of defining what adaptation looks like in practice, linking intervention to vulnerability reduction outcomes, and locating suitable data sources to facilitate systematic cross-country evaluations over time. More broadly, adaptation tracking is constrained by a lack of comparable metrics and standardized —or even standardizeable — units of analysis for measuring and quantifying climate change impacts, with adaptations implicitly aimed at aversion and/or minimization of impacts. These challenges are unlikely to be fully resolved, reflecting the inherent "messiness" of adaptation, and necessitating the development of diverse methodologies that can provide varied perspectives on adaptation progress.

In this Insight Paper we have presented a typology of approaches and tools that could be used for adaptation tracking, drawing upon research on monitoring and evaluation in the general scholarship and emerging research in a climate change context. As such we provide insights relevant to all six themes of this special edition, which is particularly important as adaptation governance becomes a key component of climate policy and research. Outcome-based approaches directly measure adaptation progress and effectiveness with reference to avoided climate change impacts. Widely regarded as the gold standard for monitoring and evaluation, their use in an adaptation context is constrained by the difficulty of attributing vulnerability reduction to adaptation, their focus on short-term tangible outcomes that only provide partial insights on adaptation success, and the fact that full climate change exposure will not happen for decades. Alternatively, a range of systematic measures are available to assess various stages of adaptation from adaptation readiness, to processes undertaken to advance adaptation, policies, and programs implemented to adapt, and measures of the impact of these policies and programs on changing vulnerability. These approaches develop indicators or proxies by which the current status of adaptation can be evaluated and monitored over time.

While some of the tools reviewed here have been piloted on a global scale, the majority of monitoring and evaluation research has not advanced beyond proposing conceptual frameworks or conducting project-specific reviews. If adaptation science is to respond to the needs of the policy community, a key goal of future research will be to apply these approaches to create a baseline understanding of current adaptation action from which to track adaptation progress. However, a key challenge to operationalization is an absence of systematically collected data on adaptation actions and outcomes across countries. Adaptation inventories for 
instance, including forums for stakeholders to voluntarily share knowledge about adaptation practices (e.g., UNDP's Adaptation Learning Mechanism, the World Resources Institute Vulnerability and Adaptation Database) and databases seeking to compile recorded adaptation in specific region (e.g., European Climate Adaptation Platform) do not provide systematic and representative data from which we can identify trends and gaps in adaptation progress globally. National Communications to the UNFCCC provide a useful source of data on adaptation from every region, but the guidelines that form the basis of the chapters concerning adaptation are brief and nonspecific, contributing to variations across reports in the level and quality of detail concerning research and interventions. Critical for future adaptation tracking initiatives is improved adaptation reporting from which to develop a baseline of current action and by which to monitor progress over time. While mitigation reporting is already well developed for inventorying emissions across sectors and countries, similar mechanisms for tracking adaptation are urgently needed and have been requested by national governments, United Nations bodies including the UNFCCC, and nongovernmental organizations.

Responses to this article can be read online at: http://www.ecologyandsociety.org/issues/responses. php/5732

\section{Acknowledgments:}

This work was supported by an Insight Development Grant from the Social Sciences and Humanities Research Council of Canada. Thanks to Anna Bunce and Carolyn Poutiainen for help with the manuscript.

\section{LITERATURE CITED}

Adger, W. N., N. W. Arnell, and E. L. Tompkins. 2005. Successful adaptation to climate change across scales. Global Environmental Change-Human and Policy Dimensions 15 (2):77-86.

Barnett, J., S. Lambert, and I. Fry. 2008. The hazards of indicators: insights from the environmental vulnerability index. Annals of the Association of American Geographers 98 (1):102-119. http://dx.doi.org/10.1080/00045600701734315

Barnett, J., and S. O'Neill. 2010. Maladaptation. Global Environmental Change-Human and Policy Dimensions 20 (2):211-213. http://dx.doi.org/10.1002/9781118529577.ch7

Berrang-Ford, L., J. D. Ford, and J. Patterson. 2011. Are we adapting to climate change? Global Environmental Change 21:25-33.
Biermann, F., P. Pattberg, and F. Zelli. 2010. Global climate governance beyond 2012: architecture, agency and adaptation. Cambridge University Press, Cambridge, UK.

Biesbroek, G. R., R. J. Swart, T. R. Carter, C. Cowan, T. Henrichs, H. Mela, M. D. Morcecroft, and D. Rey. 2010. Europe adapts to climate change-comparing national adaptation strategies. Global Environmental Change 20:440-450. http://dx.doi.org/10.1016/j.gloenvcha.2010.03.005

Brooks, N., W. N. Adger, and P. M. Kelly. 2005. The determinants of vulnerability and adaptive capacity at the national level and the implications for adaptation. Global Environmental Change-Human and Policy Dimensions 15:151-163. http://dx.doi.org/10.1016/j.gloenvcha.2004.12.006

Brooks, N., S. Anderson, J. Ayers, I. Burton, and I. Tellam. 2011. Tracking adaptation and measuring development. IIED Climate Change Working Paper No. 1. Climate Change Group, International Institute for Environment and Development (IIED), London, UK.

Burton, I. 2006. Adapt and thrive: options for reducing the climate-change adaptation deficit. Policy Options 2006 (1):33-38.

Campbell, M., R. Fitzpatrick, A. Haines, A. L. Kinmonth, P. Sandercock, D. Spiegelhalter, and P. Tyrer. 2000. Framework for design and evaluation of complex interventions to improve health. British Medical Journal 321. http://dx.doi. org/10.1136/bmj.321.7262.694

de Bruin, K., R. B. Dellink, A. Ruijs, L. Bolwidt, A. van Buuren, J. Graveland, R. S. de Groot, P. J. Kuikman, S. Reinhard, R. P. Roetter, V. C. Tassone, A. Verhagen, and E. C. van Ierland. 2009. Adapting to climate change in The Netherlands: an inventory of climate adaptation options and ranking of alternatives. Climatic Change 95:23-45. http://dx. doi.org/10.1007/s10584-009-9576-4

Dilling, L., and M. C. Lemos. 2011. Creating usable science: opportunities and constraints for climate knowledge use and their implications for science policy. Global Environmental Change - Human and Policy Dimensions 21:680-689. http:// dx.doi.org/10.1016/j.gloenvcha.2010.11.006

Donner, S. D., M. Kandlikar, and H. Zerriffi. 2011. Preparing to manage climate change financing. Science 334:908-909. http://dx.doi.org/10.1126/science.1211886

Earle, A., Z. Mokomane, and J. Heymann. 2011. International perspectives on work-family policies: lessons from the world's most competitive economies. Future of Children 21. http://dx. doi.org/10.1353/foc.2011.0014

Eriksen, S. H., and P. M. Kelly. 2007. Developing credible vulnerability indicators for climate adaptation policy assessment. Mitigation and Adaptation Strategies for Global Change 12:495-424. http://dx.doi.org/10.1007/s11027-006-3460-6 
Fankhauser, S., and I. Burton. 2011. Spending adaptation money wisely. Climate Policy 11:1037-1049. http://dx.doi. org/10.1080/14693062.2011.582389

Fazey, I., N. Pettorelli, J. Kenter, D. Wagatora, and D. Schuett. 2011. Maladaptive trajectories of change in Makira, Solomon Islands. Global Enviromental Change 21:1275-1289. http:// dx.doi.org/10.1016/j.gloenvcha.2011.07.006

Ford, J. D., and L. Berrang-Ford. 2011. Climate change adaptation in developed nations: from theory to practice. Springer.

Ford, J. D., L. Berrang-Ford, M. King, and F. C. 2010. Climate change policy responses for Canada's Inuit population: the importance of and opportunities for adaptation. Global Environmental Change 20:177-191. http://dx.doi.org/10.1016/ j.gloenvcha.2009.10.008

Ford, J. D., L. Berrang-Ford, and J. Patterson. 2011. A systematic review of observed climate change adaptation in developed nations. Climatic Change Letters 106(2):327-336. http://dx.doi.org/10.1007/s10584-011-0045-5

Ford, J. D., and D. King. 2013. A framework for examining adaptation readiness. Mitigation and Adaptation Strategies for Global Change. http://dx.doi.org/10.1007/s11027-013-9505-8

Fussel, H. M. 2007. Adaptation planning for climate change: concepts, assessment approaches, and key lessons. Sustainability Science 2:265-275. http://dx.doi.org/10.1007/ s11625-007-0032-y

Fussel, H. M. 2008. Assessing adaptation to the health risks of climate change: what guidance can existing frameworks provide? International Journal of Environmental Health Research 18:37-63.

Fussel, H. M. 2009. Development and climate change background note: review and quantitative analysis of indices of climate change exposure, adaptive capacity, sensitivity, and impacts. Background note to the World Development Report 2010. World Bank Publications, Washington D.C., USA.

Fussel, H. M., and R. T. J. Klein. 2006. Climate change vulnerability assessments: an evolution of conceptual thinking. Global Environmental Change 75:301-329.

Gagnon-Lebrun, F., and S. Agrawala. 2007. Implementing adaptation in developed countries: an analysis of progress and trends. Climate Policy 7:392-408.

Glasgow, R. E., T. M. Vogt, and S. M. Boles. 1999. Evaluating the public health impact of health promotion interventions: the RE-AIM framework. American Journal of Public Health 89. http://dx.doi.org/10.2105/AJPH.89.9.1322

Gupta, J., C. Termeer, J. Klostermann, S. Meijerink, M. van den Brink, P. Jong, S. Nooteboom, and E. Bergsma. 2010. The adaptive capacity Wheel: a method to assess the inherent characteristics of institutions to enable the adaptive capacity of society. Environmental Science \& Policy 13. http://dx.doi. org/10.1016/j.envsci.2010.05.006

Hambling, T., P. Weinstein, and D. Slaney. 2011. A review of frameworks for developing environmental health indicators for climate change and health. International Journal of Environmental Research and Public Health 8. http://dx.doi. org/10.3390/ijerph8072854

Hanger, S., S. Pfenninger, M. Dreyfus, and A. Patt. 2013. Knowledge and information needs of adaptation policymakers: a European study. Regional Environmental Change 13:91-101. http://dx.doi.org/10.1007/s10113-012-0317-2

Harley, M., L. Horrocks, N. Hodgson, and J. Van Minnen. 2008. Climate change vulnerability and adaptation indicators. ETC/ACC Technical Paper 2008/9. European Topic Centre on Air and Climate Change, European Environmental Agency, Bilthoven, The Netherlands.

Harvey, A., N. Hodgson, M. Benzie, S. Winne, R. Smithers, S. Dresner, P. Drummond, C. Colement, L. Horrocks, and M. Harley. 2011. Provision of research to identify indicators for the Adaptation Sub-Committee: final report. Adaptation SubCommittee, Committee on Climate Change, London, UK.

Heymann, J., and K. McNeill. 2013. Children's chances: how countries can move from surviving to thriving. Harvard University Press, Cambridge, Massachusetts, USA. http://dx. doi.org/10.4159/harvard.9780674067974

Heymann, J., A. Raub, and A. Earle. 2011. Creating and using new data sources to analyze the relationship between social policy and global health: the case of maternal leave. Public Health Reports 126.

Hinkel, J. 2011. "Indicators of vulnerability and adaptive capacity": towards a clarification of the science-policy interface. Global Environmental Change-Human and Policy Dimensions 21:198-208. http://dx.doi.org/10.1016/j. gloenvcha.2010.08.002

Jakeman, A. J., R. A. Letcher, and J. P. Norton. 2006. Ten iterative steps in development and evaluation of environmental models. Environmental Modelling \& Software 21(5):602-614. http://dx.doi.org/10.1016/j.envsoft.2006.01.004

Jones, H. P., D. G. Hole, and E. S. Zavaleta. 2012. Harnessing nature to help people adapt to climate change. Nature Climate Change 2:504-509. http://dx.doi.org/10.1038/nclimate1463

Kahn, M. E. 2003. Two measures of progress in adapting to climate change. Global Environmental Change-Human and Policy Dimensions 13. http://dx.doi.org/10.1016/S0959-3780 (03)00052-9

Kates, R. W., C. E. Colten, S. Laska, and S. P. Leatherman. 2006. Reconstruction of New Orleans after Hurricane Katrina: 
a research perspective. Proceedings of the National Academy of Sciences of the United States of America 103:14653-14660. http://dx.doi.org/10.1073/pnas.0605726103

Kates, R. W., C. Hohenemser, and J. E. X. Kasperson. 1985. Perilous progress: managing the hazards of technology. Westview special studies in science, technology, and public policy. Westview Press, Boulder, Colorado, USA.

Klein, R. J. T. 2009. Identifying countries that are particularly vulnerable to the adverse effects of climate change: an academic or political challenge? Carbon \& Climate Law Review 3:284-291.

Klein, R. J. T., and A. Moehner. 2011. The political dimension of vulnerability: implications for the Green Climate Fund. IDS Bulletin-Special Issue: Political Economy of Climate Change 42(3): 15-22. http://dx.doi.org/10.1111/

j.1759-5436.2011.00218.x

Krebs, Lord J., A. Dlugolecki, S. Fankhauser, J. Hall, A. Johnson, T. Palmer, M. Parry, and G. Wynne. 2011. Adapting to climate change in the UK: measuring progress. Adaptation Sub-Committee progress report 2011. Adaptation SubCommittee, Committee on Climate Change, London, UK.

Krebs, Lord J., A. Dlugolecki, S. Fankhauser, J. Hall, A. Johnson, T. Palmer, M. Parry, G. Wynne, and B. Young. 2010. How well prepared is the UK for climate change? First report of the Adaptation Sub-Committee 16 September 2010. Adaptation Sub-Committee, Committee on Climate Change, London, UK.

Lamhauge, N., E. Lanzi, and S. Agrawala. 2012. Monitoring and evaluation for adaptation: lessons from development cooperation agencies. OECD Environment Working Papers 38. http://dx.doi.org/10.1787/5kg20mj6c2bw-en

Laville, F. 2000. Foundations of procedural rationality: cognitive limits and decision processes. Economics and Philosophy 16. http://dx.doi.org/10.1017/S026626710000016X

Lemos, M. C., and B. J. Morehouse. 2005. The co-production of science and policy in integrated climate assessments. Global Environmental Change-Human and Policy Dimensions 15:57-68. http://dx.doi.org/10.1016/j.gloenvcha.2004.09.004

Lesnikowski, A., J. D. Ford, L. Berrang-Ford, M. Barrera, P. Berry, J. Henderson, and S. J. Heymann. In press-a. Nationallevel factors affecting likelihood to adapt to the health effects of climate change. Global Environmental Change.

Lesnikowsk,i A., J. D. Ford, L. Berrang-Ford, M. Barrera,and J. Heymann. In press-b. How are we adapting to climate change? A systematic approach to measuring reported adaptation at the national level. Mitigation and Adaptation Strategies for Global Change.
Lesnikowski, A. C., J. D. Ford, L. Berrang-Ford, J. A. Paterson, M. Barrera, and S. J. Heymann. 2011. Adapting to health impacts of climate change: a study of UNFCCC Annex I parties. Environmental Research Letters 6. http://dx.doi. org/10.1088/1748-9326/6/4/044009

Liverman, D., and S. Billett. 2010. Copenhagen and the governance of adaptation. Environment 52:28-36. http://dx. doi.org/10.1080/00139151003761579

McMichael, A. J., D. Campbell-Lendrum, S. Kovats, S. Edwards, P. Wilkinson, T. Wilson, R. Nicholls, S. Hales, F. Tanser, D. Le Sueur, M. Schlesinger, and N. Andronova. 2004. Chapter 20: global climate change. Pages 1543-1651 in M. Ezzati, A. D. Lopez, A. Rodgers, and C. J. L. Murray C, editors. Comparative quantification of health risks: global and regional burden of disease atrributable to selected major risk factors. Volume 2. World Health Organization, Geneva, Switzerland.

Moser, S. C., and J. A. Ekstrom. 2010. A framework to diagnose barriers to climate change adaptation. Proceedings of the National Academy of Sciences of the United States of America 107:22026-22031.

O'Brien, K., L. Sygna, and J. E. Haugen. 2004. Resilient or vulnerable? A multi-scale assessment of climate impacts and vulnerability in Norway. Climate Change 64:193-225. http:// dx.doi.org/10.1023/B:CLIM.0000024668.70143.80

Paterson, J. A., J. D. Ford, L. B. Ford, A. Lesnikowski, P. Berry, J. Henderson, and J. Heymann. 2012. Adaptation to climate change in the Ontario public health sector. BMC Public Health 12. http://dx.doi.org/10.1186/1471-2458-12-452

Pielke, R. A., G. Prins, S. Rayner, and D. Sarewitz. 2007. Climate change 2007: lifting the taboo on adaptation. Nature 445:597-598. http://dx.doi.org/10.1038/445597a

Poutiainen, C., L. Berrang-Ford, J. Ford, A. Lesnikowski, and J. Heymann. 2013. Civil society organizations and adaptation to the health effects of climate change in Canada. Public Health 127(5):403-409. http://dx.doi.org/10.1016/j.puhe.2013.02.004

Preston, B. L., R. Westaway, S. Dessai, and T. Smith. 2009. Are we adapting to climate change? Research and methods for evaluating progress. Paper presented at An Eye on Policy -AMS Annual Meeting and Fourth Symposium on Policy and Socio-Economic Research, January 2009, Phoenix Arizona. American Meterological Society, Washington, DC, USA.

Preston, B. L., R. M. Westaway, and E. J. Yuen. 2011. Climate adaptation planning in practice: an evaluation of adaptation plans from three developed nations. Mitigation and Adaptation Strategies for Global Change 16:407-438. http:// dx.doi.org/10.1007/s11027-010-9270-X 
Requejo, J., J. Bryce, and C. Victora. 2012. Building a future for women and children: the 2012 annual report. World Health Organization, Geneva, Switzerland; and UNICEF, New York, New York, USA.

Rubin, H. R., P. Pronovost, and G. B. Diette. 2001. The advantages and disadvantages of process-based measures of health care quality. International Journal for Quality in Health Care 13:469-474. http://dx.doi.org/10.1093/intqhe/13.6.469

Rychetnik, L., M. Frommer, P. Hawe, and A. Shiell. 2002. Criteria for evaluating evidence on public health interventions. Journal of Epidemiology and Community Health 56. http://dx. doi.org/10.1136/jech.56.2.119

Schliwen A., A. Earle, J. Hayes, and S. J. Heymann. 2011. The administration and financing of paid sick leave. Industrial Labour Review 150(1-2):43-62. http://dx.doi.org/10.1111/ j.1564-913X.2011.00104.X

Schonthaler, K., S. Von Andrian-Werburg, K. Wulfert, V. Luthardt, B. Kreinsen, R. Schultz-Sternberg, and R. Hommel. 2010. Establishment of an indicator concept for the German strategy on adaptation to climate change. Federal Environment Agency (Umweltbundesamt), Dessau-Roßlau, Germany.

Smit, B., and J. Wandel. 2006. Adaptation, adaptive capacity and vulnerability. Global Environmental Change-Human and Policy Dimensions 16:282-292. http://dx.doi.org/10.1016/ j.gloenvcha.2006.03.008

Smith, J. B., J. M. Vogel, and J. E. Cromwell. 2009. An architecture for government action on adaptation to climate change. An editorial comment. Climatic Change 95:53-61. http://dx.doi.org/10.1007/s10584-009-9623-1

Smith, M. S., L. Horrocks, A. Harvey, and C. Hamilton. 2011. Rethinking adaptation for a $4^{\circ} \mathrm{C}$ world. Philosophical Transactions of the Royal Society A 369:196-216. http://dx. doi.org/10.1098/rsta.2010.0277

Sovacool, B. K. 2011. Hard and soft paths for climate change adaptation. Climate Policy 11:1177-1183. http://dx.doi. org/10.1080/14693062.2011.579315

Sovacool, B. K. 2012. Expert views of climate change adaptation in the Maldives. Climatic Change 114:295-300. http://dx.doi.org/10.1007/s10584-011-0392-2

Sovacool, B. K., A. L. D'Agostino, H. Meenawat, and A. Rawlani. 2012. Expert views of climate change adaptation in least developed Asia. Journal of Environmental Management 97:78-88. http://dx.doi.org/10.1016/j.jenvman.2011.11.005

Termeer, C., R. Biesbroek, and M. Van den Brink. 2012. Institutions for adaptation to climate change: comparing national adaptation strategies in Europe. European Political Science 11. http://dx.doi.org/10.1057/eps.2011.7
Tompkins, E., W. N. Adger, E. Boyd, S. Nicholson-Cole, K. Weatherhead, and M. Arnell. 2010a. Observed adaptation to climate change: UK evidence of transition to a well-adapting society. Global Environmental Change 20(4):627-635.

Tompkins, E. L., W. N. Adger, E. Boyd, S. Nicholson-Cole, K. Weatherhead, and N. Arnell. 2010b. Observed adaptation to climate change: UK evidence of transition to a well-adapting society. Global Environmental Change-Human and Policy Dimensions 20(4):627-635.

United Nations Framework Convention on Climate Change (UNFCCC). 2010a. Report of the Conference of the Parties on its sixteenth session, held in Cancun from 29 November to 10 December 2010. Part one: proceedings. Conference of the Parties, United Nations, Geneva, Switzerland.

United Nations Framework Convention on Climate Change (UNFCCC). 2010b. Synthesis report on efforts undertaken to monitor and evaluate the implementation of adaptation projects, policies and programmes and the costs and effectiveness of completed projects, policies and programmes, and views on lessons learned, good practices, gaps and needs. Secretariat, United Nations, Geneva, Switzerland.

Villaneuva, P. S. 2011. Learning to ADAPT: monitoring and evaluation approaches in climate change adaptation and disaster risk reduction-challenges, gaps and ways forward. SCR Discussion Paper 9. Strengthening Climate Resilience Discussion Series. Institute of Development Studies, Brighton, Sussex, UK.

Yohe, G., and R. S. J. Tol. 2002. Indicators for social and economic coping capacity-moving toward a working definition of adaptive capacity. Global Environmental Change -Human and Policy Dimensions 12:25-40. 